\section{How should blindness in children be managed?}

\begin{abstract}
Background In all, 1.4 million children are estimated to be blind worldwide and only $6.5 \%$ of these are thought to come from the more affluent countries. The focus of this paper is therefore the developing world and Africa in particular, where evidence suggests that congenital cataract is becoming the leading cause of childhood blindness. Methods A review of the literature on management of congenital cataract was combined with original data from the author's experience in east Africa.

Conclusions Health service structure, surgical technique, health education, and community screening to promote early referral, good surgical follow-up, and training of multidisciplinary teams based at specialist children's eye centres are all essential components for effective strategies to control childhood blindness due to congenital cataract.
\end{abstract}

Eye (2005) 19, 1037-1043. doi:10.1038/sj.eye.6701988

Keywords: childhood; blindness; congenital; cataract; Africa

\section{Introduction - the scale and distribution of the problem}

It is currently estimated that there are 1.4 million children blind worldwide and that only $6.5 \%$ of these live in the more affluent regions of the world. ${ }^{1}$ Therefore, a paper addressing the general question of management of childhood blindness should focus on the poorer regions of the world, where the blind children are.

Reasons for this statistic include higher disease prevalence, poorer access to eye care, and the greater number of children living in developing countries compared to affluent countries. The figure is only an estimate because accurate data on childhood blindness are difficult to obtain. The usual sources are blind registers, blind
RJC Bowman

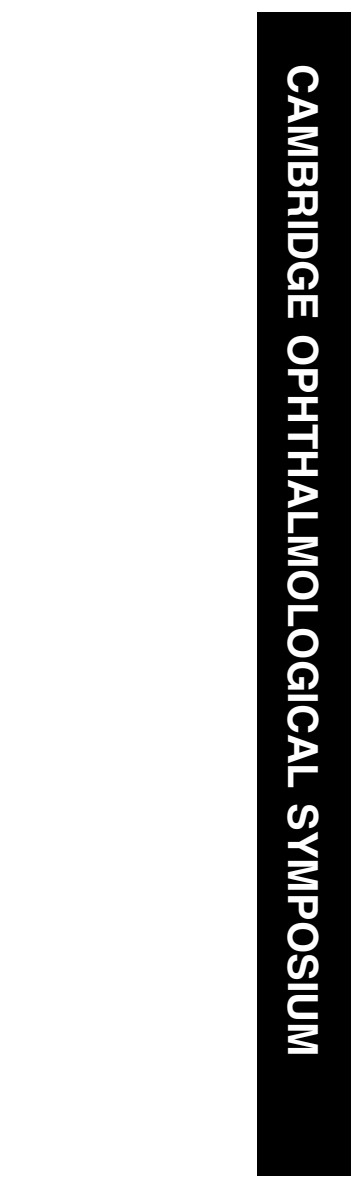

schools, and population-based surveys, and resulting data are limited by the fact that not all blind children are registered or enrolled in blind schools and by the fact that sample sizes for population-based surveys are usually based on adult blindness (which is much more common and therefore requires a smaller sample) and therefore yield very imprecise figures for childhood blindness. Available data have been collected and reclassified by anatomical cause, which is shown to vary considerably with economic geography, Table $1 .^{2}$

Although Table 1 shows corneal blindness to be the most common cause of childhood blindness in sub-Saharan Africa (due to vitamin A deficiency and measles), there is emerging evidence that cataract is now overtaking corneal disease as the leading cause of childhood blindness in Africa. Community and blind school studies in Uganda $^{3}$ and Nigeria ${ }^{4}$ have shown cataract to be the leading cause and this concurs with the experience of the author, having spent over 2 years working in Tanzania, during which hundreds of children with cataracts have been operated and only a very few patients seen with corneal scarring due to vitamin A deficiency. Although clinical experience at an urban hospital may not be generalizable to the community, an outreach bus is sent out weekly to poor rural areas, and if childhood corneal blindness was prevalent in these communities, some would be expected to reach the hospital. The reason for this change is likely to be a fall in the prevalence of corneal disease $^{3}$ due to successful immunization and vitamin A supplementation programmes and it tells us little about the incidence of cataract in childhood. The result of the change is that the challenges of managing childhood blindness in Africa now fall mainly on the shoulders of the ophthalmologist and the eye care team, rather than the public health physicians and nutritionists, and it is these challenges that are addressed in this paper, which focuses on the management of blinding childhood cataract in
CCBRT Disability Hospital, PO Box 23310, Dar es Salaam, Tanzania

Correspondence:

RJC Bowman,

Tel: + 255222600070;

Fax: + 255222602883 . intafrica.com

Received: 10 April 2005 Accepted: 2 May 2005
E-mail: richardbowman@ 
Table 1 Regional variation in the cause of blindness in children - descriptive classification by World Bank Region (\%) (total of 8343 children examined) ${ }^{\mathrm{a}}$

\begin{tabular}{|c|c|c|c|c|c|c|c|c|}
\hline & $E M E$ & FSE & $L A C$ & $M E C$ & China & India & $O A I$ & $S S A$ \\
\hline Number examined & None $^{b}$ & 504 & 1007 & 866 & 1131 & 2283 & 850 & 1702 \\
\hline Globe $(\%)$ & 10 & 12 & 12 & 14 & 26 & 25 & 21 & 9 \\
\hline Cornea (\%) & 1 & 2 & 8 & 8 & 4 & 27 & 21 & 36 \\
\hline Lens $(\%)$ & 8 & 11 & 7 & 20 & 19 & 11 & 19 & 9 \\
\hline Uvea (\%) & 2 & 5 & 2 & 4 & 1 & 5 & 3 & 5 \\
\hline Retina $(\%)$ & 25 & 44 & 47 & 38 & 25 & 22 & 21 & 20 \\
\hline Optic nerve (\%) & 25 & 15 & 12 & 8 & 14 & 6 & 7 & 10 \\
\hline Glaucoma (\%) & 1 & 3 & 8 & 5 & 9 & 3 & 6 & 6 \\
\hline Other (inc. CNS) (\%) & 28 & 8 & 4 & 3 & 2 & 1 & 2 & 5 \\
\hline Total $(\%)$ & 100 & 100 & 100 & 100 & 100 & 100 & 100 & 100 \\
\hline
\end{tabular}

$\mathrm{EME}=$ established market economies; $\mathrm{FSE}=$ former socialist market economies; LAC = Latin America and the Caribbean; MEC = Middle Eastern Crescent; $\mathrm{OAI}=$ other Asian countries and islands; SSA = sub-Saharan Africa.

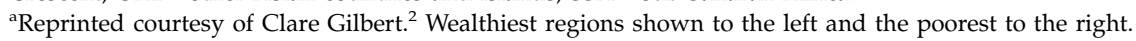

${ }^{\mathrm{b}}$ Data from published studies, which included 1683 children.

Africa and other developing countries. Two of the major challenges were illustrated well by a father and son who presented to our hospital last year (Figure 1).

\section{(a) Health service organization}

The World Health Organization has approved a strategy of limiting surgery for cataract in children to specialized tertiary centres while highlighting the importance of primary and secondary levels in facilitating early identification and referral of children to the tertiary centres. The reasons for limiting the surgery to specialist centres (even in a continent where there is a gross shortage of eye surgeons already) include the need for specialist surgical skills for which most cataract surgeons are not trained; the need for specialist surgical equipment (eg vitrectomy machines, A-scan for use in theatre, good quality intraocular lenses (IOLs), and viscoelastics); and the need for a multidisciplinary team with specialist paediatric skills including anaesthetist, nurses, optometrists, and those trained in visual assessment of children. Many of the cataract blind children identified in African studies ${ }^{3,4}$ had been operated on and the aim of restricting this surgery to specialist centres is to reduce the incidence of poor surgical results as exemplified by the father in Figure 1. The aims of Vision 2020 (the international campaign to eliminate avoidable blindness by the year 2020) include the establishment of one such tertiary children's eye care centre per 10 million population by the year 2020 and one per 20 million as an interim target by the year 2010. What is the current situation? In Tanzania, there are two such centres for a population of 35 million. Both are funded by western nongovernmental organizations (NGOs) and are led by expatriate ophthalmologists but are training national paediatric ophthalmologists. Uganda and Kenya are similarly supplied, but the situation is worse in West Africa where very few such centres exist. Bangladesh currently has seven centres for a population of about 130 million.

\section{(b) Surgical technique}

Techniques for cataract surgery in children have advanced considerably over the last decade or so with a widespread move to IOL implantation even in young babies. Although the benefits of this move remain unproven and contact lenses continue to offer an excellent alternative for populations where hygienic maintenance and regular follow-up are possible, IOL implantation does offer particular benefits to poor rural populations where follow-up may be irregular and where even aphakic spectacles, let alone contact lenses, are difficult to maintain and replace. It has also been suggested but not proven that IOL implantation may reduce the risk of postoperative glaucoma, ${ }^{5}$ which remains a troublesome and prevalent complication of cataract surgery in children. The obvious disadvantage of IOLs especially in very young children is that their eye is still growing and its refraction changing - what power of lens should be inserted? Most surgeons advocate mild undercorrection to allow for the predicted myopic shift (likely to be higher in a pseudophakic than a phakic growing eye because compensatory emmetropizing changes in lens shape cannot occur $\left.{ }^{6}\right)$. Others argue that since amblyopia is the limiting factor in visual outcome for most of these patients, emmetropia (or even myopia since an infant's visual environment is largely at near in reach of his or her hands) during the amblyogenic period is more important than emmetropia in later life and they 

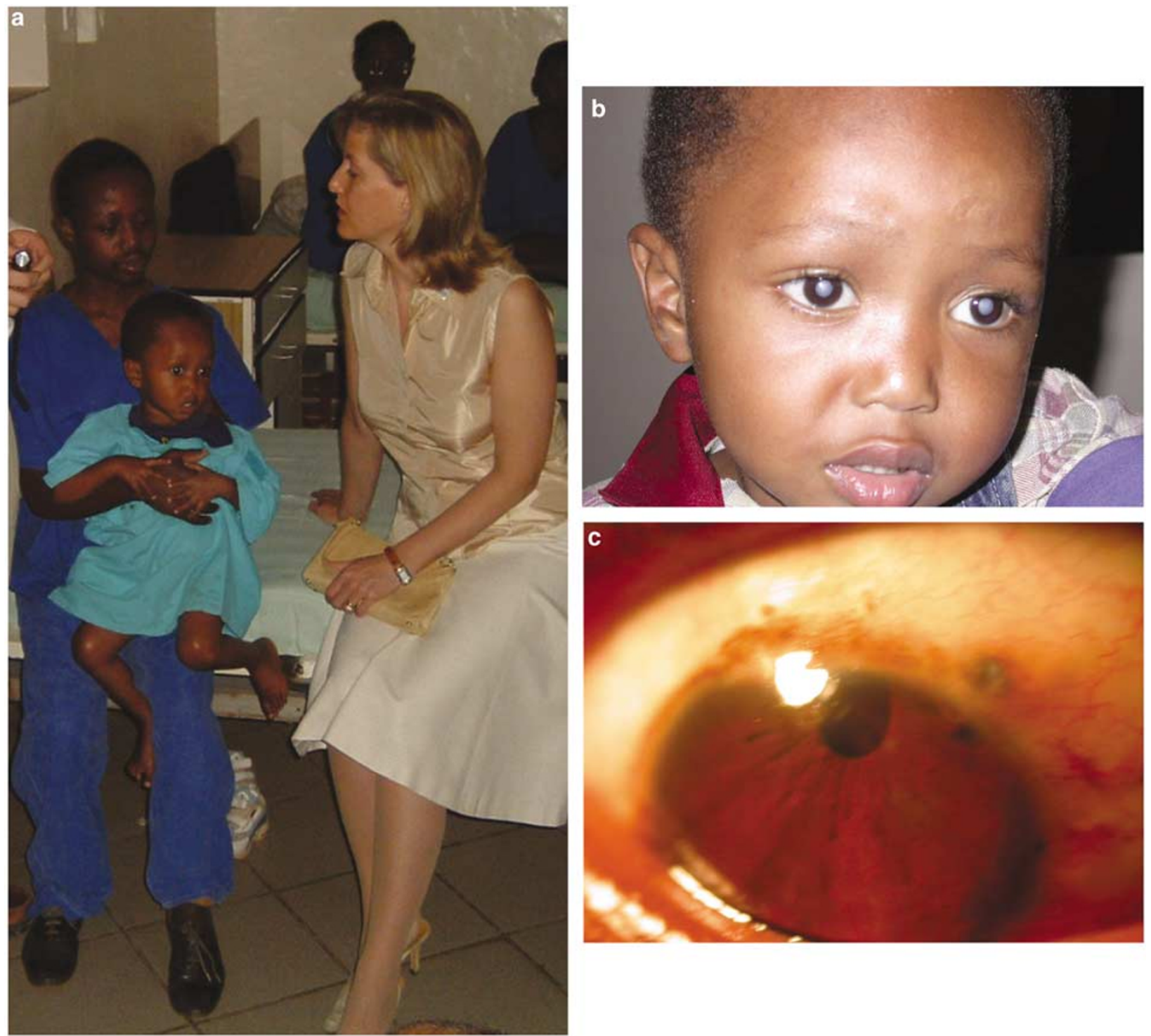

Figure 1 (a) HRH Countess of Wessex (patron of Vision 2020) meets father and son at CCBRT. Photo courtesy of Tim Rooke, Rex Pictures. (b) The son is presenting with congenital cataracts for the first time, aged 5 years. (c) One reason for the delay in presentation may have been that his father was also blind ( $20 \%$ of our cataracts in children are autosomal dominant), despite having had surgery as a child. The family illustrate two of the major problems encountered in tackling infantile cataract in Africa: late presentation and poor surgical results.

advocate full correction. There is currently no evidence to support either theory.

Concerning IOL type, there are a number of short-term reports of use of foldable hydrophobic acrylic in children. ${ }^{7-9}$ They seem to cause less acute postoperative fibrinous uveitis ${ }^{10}$ and are easier to insert into small capsular bags. The chemical structure of foldable acrylic is similar to polymethylmethacrylate (PMMA), but some paediatric ophthalmologists still feel that is safer to continue with the latter because the IOL has to last much longer in children than adults and much longer-term follow-up data are available for rigid PMMA than for the newer foldable materials. In addition to IOL

implantation, other techniques are being borrowed from modern adult cataract surgery and applied to children such as continuous curvilinear capsulorhexis (CCC) and hydrodissection. CCC aids intracapsular fixation, but may require expensive items such as high-quality viscoelastic and squeeze handle rhexis forceps in small eyes. Owing to this, Wilson advocated use of the vitrectomy cutter to perform a 'vitrectorhexis' as the standard technique for developing countries. ${ }^{11}$ In the author's experience in east Africa, the most common reason for failure to perform CCC is the tough 
consistency of a thickened anterior capsule, sometimes even resistant to cutting with a vitrector and requiring scissors, and certainly resistant to tearing in a circle. Whether these capsule changes are secondary to delayed presentation or due to different aetiology of cataract in our population is unknown. Hydrodissection has been shown to speed up aspiration of soft lens matter. ${ }^{12}$

The need for primary capsulotomy of some kind and anterior vitrectomy in younger patients is widely accepted to reduce the incidence of postoperative posterior capsular opacity (PCO), although there has been some disagreement between surgeons about what age anterior vitrectomy ceases to be necessary. Raina et $a l^{13}$ suggested posterior capture of the IOL optic through a posterior CCC as an alternative to vitrectomy for reducing PCO, but Vasavada et al ${ }^{14}$ showed in a randomized controlled trial that anterior vitrectomy performed in addition to posterior CCC reduced incidence of PCO in children aged between 5 and 12 years old. Another study suggested that posterior capture was associated with increased risk of postoperative uveitis. ${ }^{15}$ Potential alternatives to anterior vitrectomy for reducing PCO incidence are of interest since there is some evidence to link primary anterior vitrectomy with the occurrence of postoperative glaucoma. ${ }^{16,24}$

\section{(c) Visual results}

What results are centres of the type mentioned in (a) above obtaining using the techniques mentioned in (b) above? Yorston et $a l^{17}$ reported visual results of $44 \%$ better than $6 / 18$ ( $n=71$ children, follow-up $>3 / 12$ in $77 \%$, mean age $=3.5$ years) in Kenya, which is similar to a preliminary short-term audit of our figures, which showed that $47 \%$ achieved $6 / 18$ or better $(n=258$ children, mean follow-up $=20$ weeks, mean age $=6.5$ years). These figures compare favourably to visual results from the region prior to the routine use of IOLs in children, Waddell reporting only $8 \%$ of patients achieving this level in Uganda, ${ }^{3}$ but compare poorly with results of series of similar aged children from the West in which the published proportions achieving $6 / 18$ or better varies from 72 to $91 \% .^{10,18-20}$ Reasons for this might include higher complication rates such as fibrinous uveitis being more common in pigmented eyes $30 \%$ in Kenya ${ }^{17}$ ) and intracapsular fixation being less common (because of CCC difficulties outlined above). This is considered unlikely, however, since our series from Tanzania showed only 15\% fibrinous uveitis (because a move towards acrylic lenses resulted in significant reduction), but visual outcome was very similar to the Kenya series. Furthermore, our overall rate of acute and chronic postoperative complications was low and

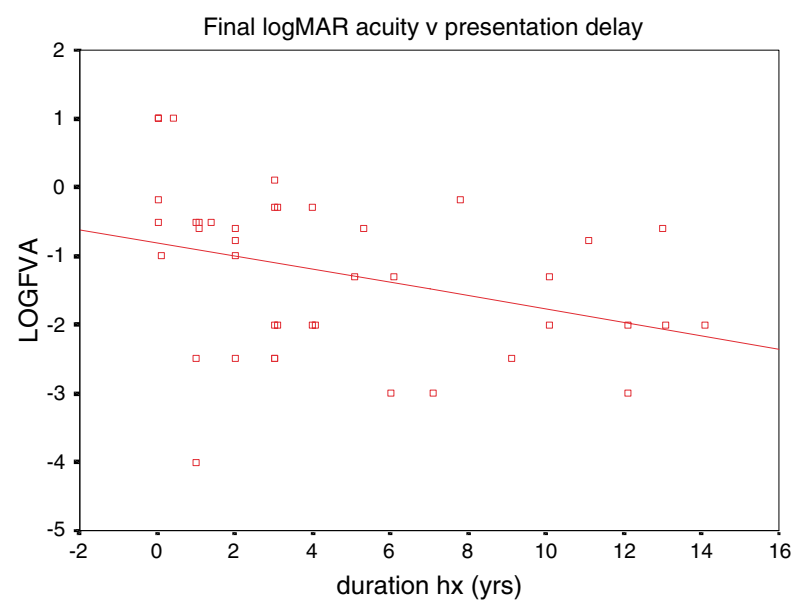

Figure 2 Linear regression plot of follow-up logMAR visual acuities against delay in presentation (years). Y-axis: logMAR acuity (converted from linear Snellen or Cardiff card acuities). $X$-axis: duration of presentation delay in years.

comparable to Western series and visual outcome was not influenced by occurrence of fibrinous uveitis or other perioperative complications. The significant factor in determining visual outcome was identified as preoperative delay in presentation (time between parents noticing a problem and presentation at our hospital, mean $=2.8$ years, $\mathrm{SD}=3.8$ years). Linear regression analysis showed linear correlation (adjusted $R^{2}=0.1$, $\mathrm{SE}=1.11, P=0.02$ ) between presentation delay and follow-up $\log$ MAR acuity (see Figure 2).

\section{(d) The effect of presentation delay and strategies to reduce it}

Figure 2 illustrates data for the first operated eye in bilateral cases only and the results are of interest on two levels:

Firstly, at the biological level they are of interest to paediatric ophthalmologists worldwide in providing evidence in support of early intervention for bilateral cataract. Early surgery and rehabilitation has become the accepted norm in the West since the work of Hubel and Wiesel on deprivation amblyopia in kittens. ${ }^{21}$ However, although there is some evidence that unilateral cataracts in humans have better visual outcomes with early surgery, ${ }^{22,23}$ there are very few data for bilateral cataract and the 'critical period' after which irreversible amblyopia develops remains unknown. Although delays such as those seen in Africa would not be advocated in the West, the benefits of very early surgery for congenital cataract have been questioned recently by data suggesting that postoperative glaucoma occurs more commonly after early surgery. ${ }^{16,24}$ Further work is 
required on this question and on establishing the critical period for humans with bilateral cataract, but the data illustrated in Figure 1 at least provide some evidence for the principle of early surgery in bilateral congenital cataract.

Secondly, it is of interest to those planning to reduce childhood blindness in Africa and other populations where delay in presentation of congenital cataract occurs. The data suggest that such delay is the most important factor in limiting visual outcome and trying to reduce this delay must be a priority target for service planners. The problem might be exacerbated by the policy outlined above of restricting surgery to tertiary centres of 1 per 10-20 million population, which increases the geographic and financial distance between the patient in the community and the service provider. Hence, the development of such tertiary centres must be accompanied by community programmes aimed at promoting early identification of congenital cataract cases, and prompt referral and facilitation of transport to the tertiary centres.

Strategies that have been tried in Africa include offering free screening in schools as a one-off week when the tertiary centre opens to raise its profile in the community (schoolchildren are older than our target age and are unlikely to be cataract blind themselves but are good messengers and may have young siblings); close liaison with, and training of, primary and secondary level government health workers and with NGOs that have high coverage in the community. The message conveyed to parents is that treatment is required urgently and that costs of transport and surgery can be subsidized or paid in full if necessary. Operational research is underway in Tanzania, Bangladesh, and India to investigate barriers to prompt presentation of congenital cataract in developing countries and strategies to address them.

\section{(e) Follow-up care}

PCO, changing refractive error, glaucoma, and amblyopia are all well-known long-term postoperative complications making close follow-up of children essential. This presents a further challenge in countries where distances are large and transport difficult. Financial inducements and reimbursements may be necessary to encourage follow-up. Follow-up consultations require specialist skills such as refraction and visual assessment unlikely to be available in secondary level centres so repeated returns by the patient to the tertiary centre are necessary. In Africa, there is no cadre of orthoptists and training people to assess vision in children is carried out in conjunction with low vision training, which is undertaken by a variety of professionals including nurses, optometrists, and teachers. The combination of skills in visual assessment of children and low vision therapy is useful in our setting where only about half our children achieve normal visual acuity postoperatively according to World Health Organization standards.

Continuing assessment of these children's functional vision and their ability to access educational material is as essential as medical follow-up, otherwise much of the benefit of the whole intervention may be lost. Sadly there are still many cataract blind children in blind schools in Africa. In some cases, they have not been referred for surgery, in others, they have had poor surgery by surgeons inadequately trained or with inadequate facilities, and in yet other cases they may have had good surgery but too late to prevent amblyopia. Many postoperative children might be able to access sighted educational material with adequate assessment and support. For example, one blind school survey from Kenya and Uganda found that $36 \%$ of children would benefit from an optical low vision device. ${ }^{25}$ Liaison between the tertiary centres and blind schools and mainstream schools with low vision units is essential as are studies to investigate the longer-term functional and educational status of these patients.

\section{(f) Training}

Since a specialist multidisciplinary team is required to manage this condition, the considerable training requirements are a priority for those planning strategies to combat childhood cataract blindness. International south south collaboration has begun on this with teams being sent to established centres for training with a view to establishing new units. The high volumes of surgery performed in these units in developing countries mean that the surgical skills can potentially be taught and acquired more quickly than is the case in the West, where it can be difficult for trainees to acquire much surgical experience but equal importance must be placed on the clinical skills required to manage the condition, particularly with regard to follow-up care. The term paediatric-orientated ophthalmologist or 'POO' has been coined to emphasize that while discouraging adult cataract surgeons from performing occasional paediatric surgery without proper training or equipment, on the other hand, it is not helpful (in the developing world where eye surgeons are in short supply) to restrict such surgery to fully fledged fellowship-trained paediatric ophthalmologists. For instance, detailed knowledge of strabismus might be desirable but is not essential in the management of childhood cataract blindness. What are needed are competent adult cataract surgeons who have undergone a specific period of training and supervision 
in the theory and practice of childhood cataract management and who have an adequate professional team and technological support to be able to use their acquired skills effectively. North south training collaborations can also prove useful such as telemedicine links or twinning partnerships between tertiary children's centres from the developed and the developing world.

\section{Summary}

Despite considerable recent advances in surgical technique, cataract is an increasingly important cause of blindness in children in Africa and remains a significant cause worldwide. A variety of specialist skills and equipment is required for preventing or curing this blindness, and therefore, even in the developing world, management of the condition should be undertaken at specialist centres. Long delays in presentation are too common in developing countries and our data suggest that this is the most important factor in limiting visual outcome, highlighting the need for better liaison between the specialist tertiary centre and primary and secondary level health workers and other community workers with high coverage access to children in order to facilitate earlier identification and referral. Owing to amblyopia, many children remain visually impaired after surgical and optical management of the cataract and close followup by both medical staff and low vision therapists liasing with schools is required to optimize accessibility to education for these children. The Vision 2020 target is to achieve one tertiary children's eye centre per 10 million of the population by the year 2020 - if this is to be achieved, then training the multidisciplined teams to staff them and development of programmes for early community case finding and referral are the two major priorities.

\section{Acknowledgements}

The author wishes to thank Drs Mark Wood and Joy Kabiru for their help in managing these patients and to Christian Blind Mission and the London School of Hygiene and Tropical Medicine for their support.

\section{References}

1 Gilbert C, Foster A. Childhood blindness in the context of VISION 2020 - the right to sight. Bull World Health Organ 2001; 79(3): 227-232.

2 Gilbert C, Rahi JS, Quinn GE. Visual impairment and blindness in children. In: Johnson GJ, Minassian D, Weale R (eds). The Epidemiology of Eye Disease, Vol. 16 Chapman \& Hall Medical: New York, 2001 p 267.
3 Waddell KM. Childhood blindness and low vision in Uganda. Eye 1998; 12(Part 2): 184-192.

4 Ezegwui IR, Umeh RE, Ezepue UF. Causes of childhood blindness: results from schools for the blind in south eastern Nigeria. Br J Ophthalmol 2003; 87(1): 20-23.

5 Asrani S, Freedman S, Hasselblad V, Buckley EG, Egbert J, Dahan E et al. Does primary intraocular lens implantation prevent 'aphakic' glaucoma in children? J AAPOS 2000; 4(1): 33-39.

6 McClatchey SK, Parks MM. Theoretic refractive changes after lens implantation in childhood. Ophthalmology 1997; 104(11): 1744-1751.

7 Stager Jr DR, Weakley Jr DR, Hunter JS. Long-term rates of PCO following small incision foldable acrylic intraocular lens implantation in children. J Pediatr Ophthalmol Strab 2002; 39(2): 73-76.

8 Mullner-Eidenbock A, Amon M, Moser E, Kruger A, Abela C, Schlemmer Y et al. Morphological and functional results of AcrySof intraocular lens implantation in children: prospective randomized study of age-related surgical management. J Cataract Refract Surg 2003; 29(2): 285-293.

9 Vasavada AR, Trivedi RH, Nath VC. Visual axis opacification after AcrySof intraocular lens implantation in children. J Cataract Refract Surg 2004; 30(5): 1073-1081.

10 Wilson ME, Elliott L, Johnson B, Peterseim MM, Rah S, Werner $\mathrm{L}$ et al. AcrySof acrylic intraocular lens implantation in children: clinical indications of biocompatibility. J AAPOS 2001; 5(6): 377-380.

11 Wilson ME, Pandey SK, Thakur J. Paediatric cataract blindness in the developing world: surgical techniques and intraocular lenses in the new millennium. Br J Ophthalmol 2003; 87(1): 14-19.

12 Vasavada AR, Trivedi RH, Apple DJ, Ram J, Werner L. Randomized, clinical trial of multiquadrant hydrodissection in pediatric cataract surgery. Am J Ophthalmol 2003; 135(1): 84-88.

13 Raina UK, Gupta V, Arora R, Mehta DK. Posterior continuous curvilinear capsulorhexis with and without optic capture of the posterior chamber intraocular lens in the absence of vitrectomy. J Pediatr Ophthalmol Strab 2002; 39(5): 278-287.

14 Vasavada AR, Trivedi RH, Singh R. Necessity of vitrectomy when optic capture is performed in children older than 5 years. J Cataract Refract Surg 2001; 27(8): 1185-1193.

15 Vasavada AR, Trivedi RH. Role of optic capture in congenital cataract and intraocular lens surgery in children. J Cataract Refract Surg 2000; 26(6): 824-831.

16 Rabiah PK. Frequency and predictors of glaucoma after pediatric cataract surgery. Am J Ophthalmol 2004; 137(1): 30-37.

17 Yorston D, Wood M, Foster A. Results of cataract surgery in young children in east Africa. Br J Ophthalmol 2001; 85(3): 267-271.

18 Gimbel HV, Basti S, Ferensowicz M, DeBroff BM. Results of bilateral cataract extraction with posterior chamber intraocular lens implantation in children. Ophthalmology 1997; 104(11): 1737-1743.

19 Peterseim MW, Wilson ME. Bilateral intraocular lens implantation in the pediatric population. Ophthalmology 2000; 107(7): 1261-1266.

20 Cassidy L, Rahi J, Nischal K, Russell-Eggitt I, Taylor D. Outcome of lens aspiration and intraocular lens 
implantation in children aged 5 years and under. $\mathrm{Br} \mathrm{J}$ Ophthalmol 2001; 85(5): 540-542.

21 Wiesel TN. Postnatal development of the visual cortex and the influence of environment. Nature 1982; 299(5884): 583-591.

22 Birch EE, Swanson WH, Stager DR, Woody M, Everett M. Outcome after very early treatment of dense congenital unilateral cataract. Invest Ophthalmol Vis Sci 1993; 34(13): 3687-3699.
23 Lloyd IC, Dowler JG, Kriss A, Speedwell L, Thompson DA, Russell-Eggitt I et al. Modulation of amblyopia therapy following early surgery for unilateral congenital cataracts. Br J Ophthalmol 1995; 79(9): 802-806.

24 Vishwanath M, Cheong-Leen R, Taylor D, Russell-Eggitt I, Rahi J. Is early surgery for congenital cataract a risk factor for glaucoma? Br J Ophthalmol 2004; 88(7): 905-910.

25 Silver J, Gilbert CE, Spoerer P, Foster A. Low vision in east African blind school students: need for optical low vision services. Br J Ophthalmol 1995; 79(9): 814-820. 